\title{
Strategy development and cross-linguistic transfer in foreign and first language writing
}

\begin{abstract}
In an increasingly multilingual world, empirical knowledge about the reciprocal influence between the mother tongue (L1) and a learner's acquisition of foreign languages (FL) is crucial yet remains surprisingly scarce. This paper examines how an explicit focus on metacognitive strategy use within a FL (German) classroom impacts students' development of writing strategies in the FL, and whether any such effects transfer to another FL (French) and/or to the L1 (English). Based on a quasi-experimental design, the study involved a two-phase intervention of strategy-based instruction primarily in the FL classroom and later also in the English classroom in a secondary school in England. Data were collected using writing strategy task sheets. Key findings indicate high levels of cross-linguistic transfer, both from one FL context to another and from FL - L1, evidenced especially by an improvement in the quality of students' planning and a reduction in the number of errors. Findings support the development of a multilingual, strategy-based pedagogy for writing where L1 and FL teachers collaborate to encourage and facilitate connection-making across language contexts.
\end{abstract}

Keywords: language learning strategies; writing; cross-linguistic transfer

\section{Introduction}

In an increasingly multilingual world, the way in which learners draw on their mother tongue (L1) and knowledge of other languages when learning a foreign language (FL) and, equally, the role of the FL in reinforcing the use of the L1 in various ways, takes on increasing importance. The current study, which focuses on writing strategies, was conceived to investigate the potential contribution of FL learning to writing development more generally. While there is some evidence to suggest that effective 
strategy use can be beneficial for language learners, the vast majority of this research has taken place within a single context of either L1 or FL education and has had a tendency to neglect the potential interactions between the two. As suggested by Griffiths and Oxford (2014:8), there has been "insufficient cross-disciplinary interchange" between strategy researchers. In addition, it is often taken for granted within the literature that any reference to transfer between these two contexts implies the one-way transfer of preexisting skills and strategies from the L1 to the FL.

However, the focus of this study emerged from a hypothesis that the reverse may be equally valid; if the use of metacognitive writing strategies is explicitly developed within the FL classroom, where learners are engaged in more explicit thought about language, then it seems logical that this knowledge could not only benefit FL writing tasks, but may also positively affect L1 writing. This article is drawn from a wider study which also considered the impact of strategy instruction on proficiency and the role of individual differences (see Forbes 2016, 2018); however, the focus here is on students' strategy development and transfer at a whole-class level. The overarching aim is to explore how an explicit focus on metacognitive strategy use within FL (German) lessons impacts students' strategy development in the FL, and whether any such effects transfer to a second FL (French) and/or to the L1 (English).

\section{Literature review}

\subsection{Metacognitive strategies in FL writing}

This study is situated within the wider theoretical framework of language learning strategies, which are generally considered as a means of ensuring that language is stored, retained and able to be produced when necessary; that is, they affect learning directly. They are "optional” (Bialystok 1978:69), "consciously selected by the learners" (Cohen 1998:4) and aim to "enhance comprehension, learning, or retention of new information" (O’Malley and Chamot 1990:1). These definitions arise from a series of assumptions about the way in which human beings process information, and therefore reflect the origins of language learning strategy research in the field of cognitive psychology. 
Another key characteristic of learning strategies emphasised by Cohen (2011) and Oxford (2017) is their close link with increasing learner autonomy, which has become a significant concern in modern classrooms.

While an increasing number of studies in recent years have provided evidence that strategy-based instruction (SBI) can be beneficial to language learners (e.g. Cohen 2011), it is important to acknowledge the complex range of variables which may facilitate or hinder this process. In a meta-analysis of studies into second language strategy instruction, Plonsky (2011) detected only a small to medium overall effect and found that effectiveness was moderated by factors such as the learning context and length of intervention. In a more recent meta-analysis, however, Ardasheva, Wang, Adesope and Valentine (2017) found that strategy instruction positively influences both foreign and second language learning with medium to large overall effects, which were almost two times larger than those reported by Plonsky (2011). The authors note that the difference may be due to the greater emphasis of more recent interventions of strategy instruction on self-regulated learning, and particularly on the metacognitive component. It is precisely this metacognitive aspect of strategy use which forms the focus of the current study.

Initially, metacognitive strategies were considered to some extent to be a distinct group of language learning strategies, which, according to O'Malley and Chamot (1990:8), involved "thinking about the learning process, planning for learning, monitoring of comprehension or production while it is taking place, and self-evaluation after the learning activity". However, it is important to recognise that strategies themselves are not necessarily inherently metacognitive; rather it is the approach learners take to a strategy and their awareness of engaging in the strategy which makes it metacognitive. This may also extend to the metacognitive use of strategies to manage social interactions and affective states (Griffiths 2013:13).

The decision to focus primarily on strategies with a metacognitive function in the current study was influenced by three key factors:

a) There is evidence of a correlation between learners' success and the use of metacognitive strategies (Cohen 2011; O’Malley and Chamot 1990); 
b) Metacognitive strategies have been identified as a vital component of any form of strategy use; it is the metacognitive element which helps learners to select, manage and transfer strategies (Grenfell and Macaro 2007);

c) Practical considerations also contributed to this focus, because if learners are metacognitively aware of the strategies they are using, they are more likely to be able to articulate them, an important consideration when conducting empirical research with young secondary school aged students.

Much of the research carried out in the field of strategy use in second language education to date has focused on the receptive skills of reading and listening. Yet it has been suggested that "writing in a second language is arguably the most difficult of the modalities in which to achieve communicative competence" (Chamot 2005:121) and therefore students can benefit from developing strategies to aid them with such a cognitively demanding task. In addition, unlike speaking, which can be acquired naturally provided that there is a sufficient level of input and exposure, writing is a skill which has to be learned and consciously developed. The luxury of time to monitor language production while writing is also conducive to the investigation and development of metacognitive strategy use in a classroom setting (Williams 2012:321).

\subsection{The phenomenon of transfer}

Of particular interest to this study is the potential for the transfer of these strategies from one language context to another. The phenomenon of transfer has been described as "a perennial issue" (Manchón and de Haan 2008:2) in second language (L2) writing research. Transfer was first conceptualised in the field of second language acquisition as the (predominantly unidirectional) influence of a learner's pre-existing L1 knowledge and habits on L2 learning and performance, and has been commonly referred to as language transfer (Odlin 1989).

Such links between the L1 and L2 have long been recognised: Cummins (1979:222), for example, proposed a linguistic interdependence hypothesis whereby the development of certain competencies in an L2 "is partially a function of the type of competence already developed in L1". He hypothesised an underlying proficiency that is 
common across languages and which allows for the transfer of literacy-related skills, after a certain level of language proficiency has been reached. Although in principle Cummins' interdependence hypothesis does not preclude L2 - L1 transfer, he attributed the lack of transfer in this direction to the absence of motivation and exposure to an L2 or FL environment (Cummins 1981).

Within the context of strategy research and in light of prevailing views on transfer, Kellerman (1991) dismissed the importance of the teaching of strategies in the L2 classroom, suggesting that learners would already have developed strategies from the learning of their L1, and could simply transfer these to the L2. There is evidence to suggest that such transfer can indeed take place and that writing strategies developed in the L1 can be used in the L2 (Jones and Tetroe 1987). However, strategies transferred from the L1 may not necessarily be effective. Additionally, many writers are considered to be 'unskilled' or 'novice' writers even in their native language, and therefore may not have developed effective strategies which they can transfer to the learning of a new language (Flower and Hayes 1981; Bereiter and Scardamalia 1987). Even skilled L1 writers may not "automatically transfer the strategies they learn in one context to a different situation" (Rubin et al. 2007:147).

However, more recently the original conceptualisation of transfer has been felt to be too restrictive, and focus has gradually shifted beyond a preoccupation with a unidirectional form of transfer from the $\mathrm{L} 1$ to the $\mathrm{L} 2$, to a more dynamic and multidirectional notion of transfer incorporating third language acquisition and multilingualism. Such a reinterpretation of transfer was supported by the advent of the concept of multicompetence, which advocates that L1 and L2 (and indeed any additional languages) are not separate systems delineated by clear boundaries, but are instead merged or overlapping systems which exist in one mind and are continuously developing (Cook 2002; Cook 2008). Multicompetence therefore assumes that someone who knows two or more languages perceives language, including their native language, differently to a monolingual speaker. As such, this has opened up new avenues of research into 'reverse transfer' from the L2 to the L1 and other forms of transfer (Cenoz, Hufeisen and Jessner 2001; Rinnert, Kobayashi and Katayama 2015). James (2006:157) in turn suggests that such transfer between different languages or contexts can be encouraged by 
metacognitive reflection, that is, "when students think relatively deeply about their own learning process and outcomes".

Therefore, it would seem logical that FL teachers, who have the opportunity to focus more explicitly on language learning strategies in the classroom, are in a unique position to contribute to the improvement of writing standards in both $\mathrm{L} 1$ and the FL. As stated by Pomphrey (2000:278):

The very act of consciously learning a language in the classroom implies a distancing of the self from the usual unconscious habits of everyday communication. This means that explicit knowledge about language as a system is likely to be more easily extracted from the foreign language learning experience than from learning which takes place in the L1.

However, there is little research on the transfer of strategies in second language acquisition and this becomes even more limited when searching for studies which actually explore the possible effect of L2 strategy instruction on both L1 and L2 writing. Although not situated within the framework of strategy research, a small number of studies have been conducted into the L2 - L1 transfer of writing features between languages.

One of the most relevant to the current study is that conducted by Berman (1994) in Iceland, which examined the bidirectional transfer of writing skills between Icelandic (L1) and English (L2) among 126 upper secondary school English as a foreign language learners. He found that following an explicit intervention of writing instruction, students' transfer of essay writing skills was more evident from the L2 to the L1 than from the L1 to the L2 and suggested that the latter may have been limited by a lack of grammatical proficiency in the L2. Kesckes and Papp (2000) similarly focused on the writing development of secondary school learners of English, French or Russian in Hungary. While this study did not include an element of intervention, participants were grouped according to intensity of FL instruction: the immersion group received instruction in other curriculum subjects through the medium of the FL, the specialised group received seven to eight hours of FL instruction per week and the control group received three hours per week. The students completed writing tasks in both the L1 and FL over a twoyear period and analysis focused on the use of syntactic structures, specifically the use of 
complex sentences and the frequency and type of subordinates. The researchers found that FL learning can facilitate L1 development significantly, however concluded that not all kinds of FL learning lead to the development of multicompetence or FL - L1 transfer. In their study, gains were evident among both the immersion and specialised groups, who showed evidence of more sophisticated written planning, improved construction of subordinate clauses and more complex embedded sentences in the L1, however this was not evident among the control group who had less intensive exposure to and less proficiency in the FL. The authors suggest, therefore, that "multicompetence seems to begin to develop only after a certain threshold in the subsequent language is reached" (Kecskes and Papp 2000:52).

The current study, therefore, explores the following research question: How does an explicit focus on metacognitive strategy use within secondary school FL lessons impact students' strategy development in the FL, and to what extent do any such effects transfer within and between the FL and L1 contexts?

\section{Methodology}

This study was conducted in a secondary school in England. The majority of students were first language English speakers learning both French and German as FLs, and had all completed at least two years of foreign language learning. ${ }^{1}$ Two parallel Year 9 classes (students aged 13-14) were selected; one was designated as the Experimental Group (EG), which received an intervention of SBI initially in the German classroom, and later also in the English classroom, and the other as a Control Group (CG), which continued with the normal scheme of work in each subject. All three languages were taught to the students in their intact classes, and the EG and CG were relatively comparable in terms of variables such as the spread of gender and range of academic performance. There were 22 and 23 participating students in each group respectively.

\footnotetext{
1 The only exceptions to this were four advanced bilingual learners (two in each class) who spoke either Mandarin or Polish as their L1. However, they had all been living in England for at least five years before the start of the study.
} 


\subsection{Overview of research design}

The study was based on a quasi-experimental design outlined in Figure 1.

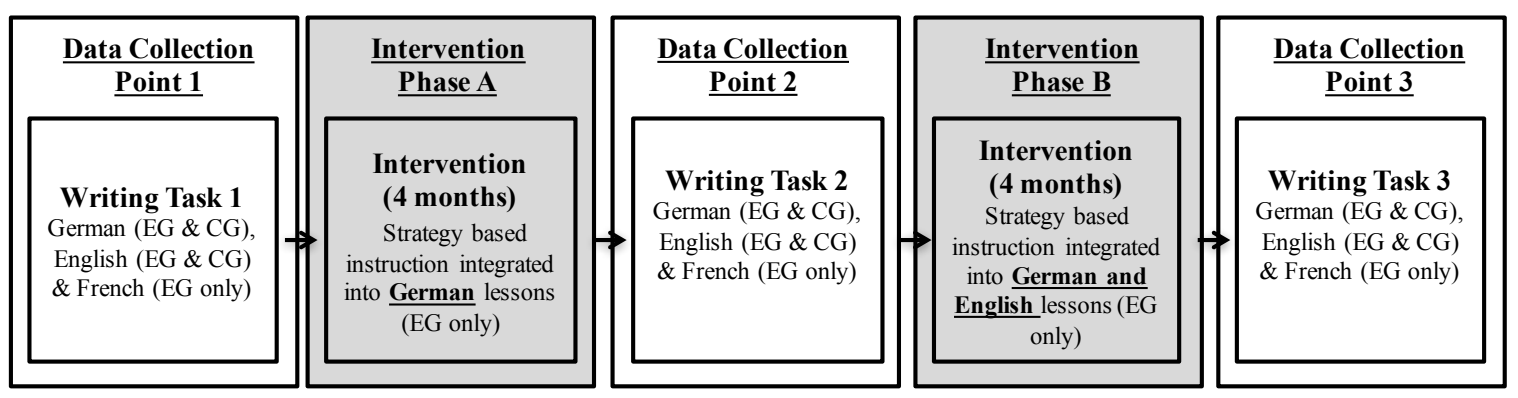

Figure 1: Research design

At Point 1 of the study, baseline data were collected to explore which writing strategies learners used in English and the FLs; students were asked to complete a writing task in German (EG+CG), French (EG only) ${ }^{2}$ and English $(E G+C G)$ on a specially designed writing task sheet (see below).

This information was then used to develop an intervention of SBI to be carried out in the German classroom of the EG in partnership with the classroom teacher over the course of four months (Phase A). The SBI was designed to be integrated into the existing scheme of work and involved the introduction of activities to aid the planning, monitoring and evaluation of written work and to encourage students to reflect on and assess their personal learning strategies and approaches. For example, this included a focus on the planning of language features, developing problem-solving strategies such as using a dictionary, and different ways to check over work in order to improve levels of accuracy. The stages of instruction were based on the recursive steps described in Table 1, in line with models of SBI proposed by Chamot (2005), Oxford (2011) and Macaro (2001).

\footnotetext{
2 Due to logistical constraints within the school it was not possible to gather French data from the CG.
} 
Table 1: Stages of strategy-based instruction

\begin{tabular}{|c|c|c|}
\hline & Stage & Examples \\
\hline 1 & $\begin{array}{l}\text { Raise awareness of the strategies } \\
\text { learners are already using }\end{array}$ & $\begin{array}{l}\text {-Whole-class and peer discussions of strategy use } \\
\text {-Co-construction of a list of existing writing strategies by } \\
\text { teacher and students }\end{array}$ \\
\hline 2 & $\begin{array}{l}\text { Teacher presents and models } \\
\text { strategies }\end{array}$ & $\begin{array}{l}\text {-Gradual presentation of strategies by teacher } \\
\text {-Modelling of strategies using think alouds } \\
\text {-Explicit explanation of rationale for using strategy }\end{array}$ \\
\hline 3 & Students practise using strategies & $\begin{array}{l}\text {-Use of scaffolding sheets for guided practice with } \\
\text { gradual removal of explicit guidelines }\end{array}$ \\
\hline 4 & $\begin{array}{l}\text { Evaluate the effectiveness of } \\
\text { strategies used and transfer strategies } \\
\text { to new tasks }\end{array}$ & $\begin{array}{l}\text {-Systematic reflection on strategy use through discussions } \\
\text { and evaluation sheets }\end{array}$ \\
\hline
\end{tabular}

Next, a second set of measures were taken in order to investigate whether or not this explicit focus on metacognitive strategy use in German lessons affected students' strategy use in German, and also whether any of the students transferred these strategies to their French or English writing tasks without any explicit encouragement to do so. During Phase B of the intervention, which also took place over the course of four months, the SBI continued in the German classroom, however was also explicitly reinforced in the English classroom of the EG. Similar activities and resources were used by both teachers in order to encourage learners to transfer the skills and strategies they developed in one curriculum area to another. A third and final set of data was then collected in order to explore any further changes which took place as a result of this additional explicit strategy instruction in English.

\subsection{Writing strategy task sheets}

At each of the three data collection points the students in both the EG and CG were asked to complete a narrative-style writing task during their English, German and French lessons. For example, the topics for the first set of tasks were: writing an email introducing yourself and your family (German), writing a description of a family in a photograph (French) and writing about a journey you have taken (English). In order to 
capture information about their strategy use, each of the tasks were completed on a writing strategy task sheet, based on a method used by Macaro (2001) in the Oxford writing strategies study. The task sheets were divided into three main sections. Firstly, a space was provided for students to use for optional pre-task planning. The next section consisted of space for students to complete the main writing task. Instructions were given at the top of the sheet which asked students to underline as they went along anything they looked up in a dictionary or textbook, and if they got stuck or sought help from the teacher or a peer. There was a blank margin down the right-hand side for them to add any notes, such as which resources were used for help or if they wanted to say something but couldn't. In order to see the extent to which students corrected, edited and rephrased their work, they were also asked not to completely erase any mistakes or changes they made, but to simply put a line through it.

The final section of the task sheet consisted of a series of questions about the evaluation process. Students were asked to indicate whether they had checked over their writing and if so, whether they did this at the end, or as they went along. As the writing strategy task sheets required students to report their strategy use relating to a specific and contemporaneous task, it was felt that this would provide a more accurate reflection of their behaviour than a more general questionnaire. Additionally, students were given the space to add their own thoughts and notes and were not restricted to selecting from a predetermined list. The use of the task sheets allowed for the writing tasks to be completed simultaneously by the whole class under normal classroom conditions, as it was felt that this would lead to more authentic findings rather than individually conducting think aloud protocols with each student in isolation.

It is also important to acknowledge that the use of prompts on the task sheet may have acted as a form of awareness-raising and perhaps even an intervention in itself. Yet as Cohen, Weaver and Li (1998:147) state, "the power of suggestion alone is not usually enough to produce strategy use". Furthermore, exactly the same data collection instruments were used with both the EG and the CG in order to control for this.

\subsection{Methods of analysis}


In total, there were 336 writing tasks, which were typed verbatim into word processing software and coded using NVivo software. The coding scheme was organised into four main categories, as outlined below. These general categories are in line with those identified in the literature (e.g. O'Malley and Chamot 1990). The more fine-grained sub-codes emerged from the data.

a) Planning: related to any pre-task planning completed by students and covered a range of features of planning, such as content items (e.g. bullet points of topics to be covered), language features (e.g. past tense, rhetorical questions) and approaches to planning such as drafting (at sentence, paragraph or text level) and language of planning.

b) Monitoring: designed to capture problem-solving strategies used by students while writing, such as the use of reference materials or asking for help from peers or the teacher. This included notes made by students in the margins of the task sheet.

c) Errors and error correction: errors made and corrected were coded in order to provide an objective measure of the effectiveness of a range of strategies used by students in order to improve the accuracy of their work. Errors made and corrected were coded in four categories: grammar, punctuation, spelling and vocabulary.

d) Evaluation: consideration of whether the students checked their work, and if so what and how they checked. This was based on responses to the questions at the end of the task sheet.

Once all of the writing tasks had been coded, a sample of the coded tasks were checked for consistency by teachers of English, German and French accordingly to ensure accuracy and reliability. Then a table of frequency counts was created for each code, for each class, in each language and at each data collection point. This was then exported into SPSS software for analysis. Some of the data were presented descriptively using text, tables and figures, and some of the data were further analysed using a series of non-parametric tests. The decision was made to use non-parametric tests due in part to the small sample size and to the non-normal distribution of data. Mann Whitney $U$ tests were used to compare the distribution of errors between the EG and CG, McNemar tests 
were used to compare the proportion of students who engaged in planning within a class between time points, and Friedman's ANOVA tests were used to compare the difference in the distribution of errors within a group over the three time points. A significance level of .05 was used for all statistical analyses and where a $Z$ score was provided this was used to calculate the effect size $(r)$.

\section{Results}

\subsection{Planning}

Planning strategies within the context of this study are defined as any written pretask preparation. Planning was first analysed in terms of students' engagement in planning, that is, whether any form of planning was undertaken or not and then in terms of the quality of planning.

Engagement in planning. First, it is worth considering the number of students who engaged in any form of written planning in each of the three languages over time, as outlined in Figure 2. Measures at Point 1 were taken pre-intervention, at Point 2 following Phase A of the intervention, and at Point 3 at the end of Phase B of the intervention.

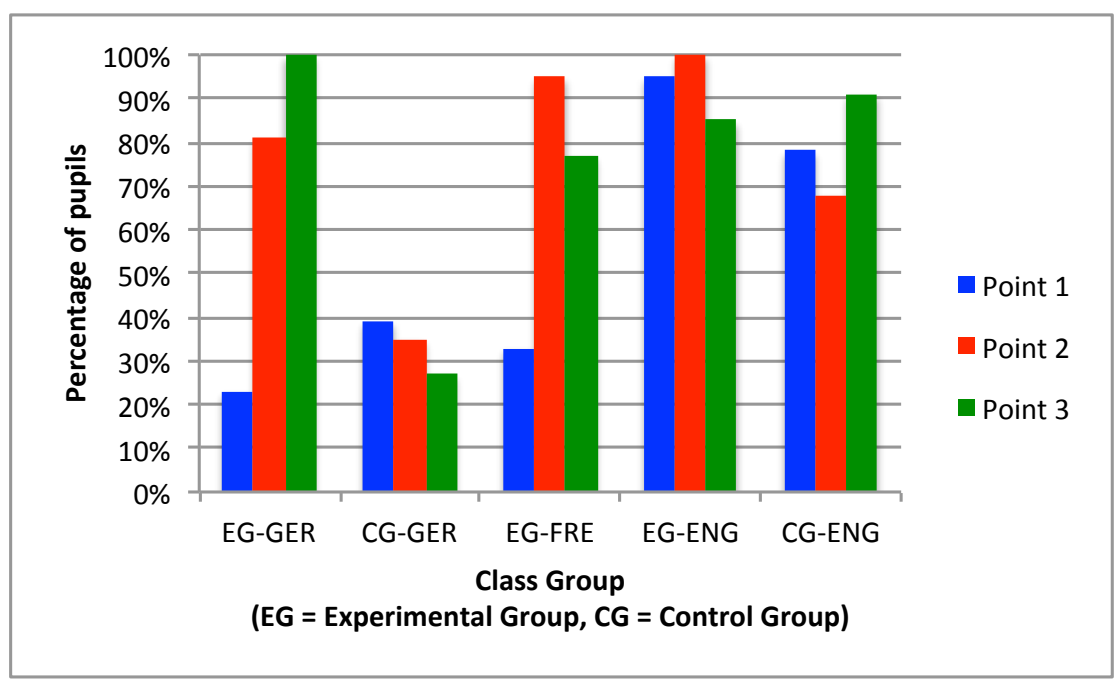

Figure 2: Percentage of students engaging in planning 
It is interesting to note that at Point 1 , students in both classes were much more likely to engage in planning in English than in German or French. This suggests that even though the majority of students used planning strategies in their L1, they did not automatically transfer these to a FL. In both FLs there was an increase in the number of students in the EG who engaged in planning following the SBI. An exact McNemar's test confirmed that this increase was significant between Points 1 and 2 for both German ( $p=$ $.002)$ and for French $(p=<.001)$. For the EG, very similar patterns emerged for both FLs, suggesting that there was perhaps some form of implicit or automatic transfer taking place; even though they were not being explicitly instructed to engage in planning strategies in their French lessons, many of them did so. Similar patterns were not reflected in the CG, where engagement in planning actually decreased over time in German. For English, there was less change in the level of engagement with planning, perhaps due to levels being very high to begin with.

Quality of planning. However, it is also important to consider what and how the students planned in order to establish whether any changes or transfer occurred as a result of the SBI, particularly for English where the number of students who engaged in planning remained high. This was considered in terms of students' general approach to planning, for example, whether they chose to draft and re-draft their work. Then specific features of planning were also considered, such as the planning of content items, language features, structure, style, use of resources and goal-setting, as shown in Figure 3 (see Appendix A for table of frequencies). 


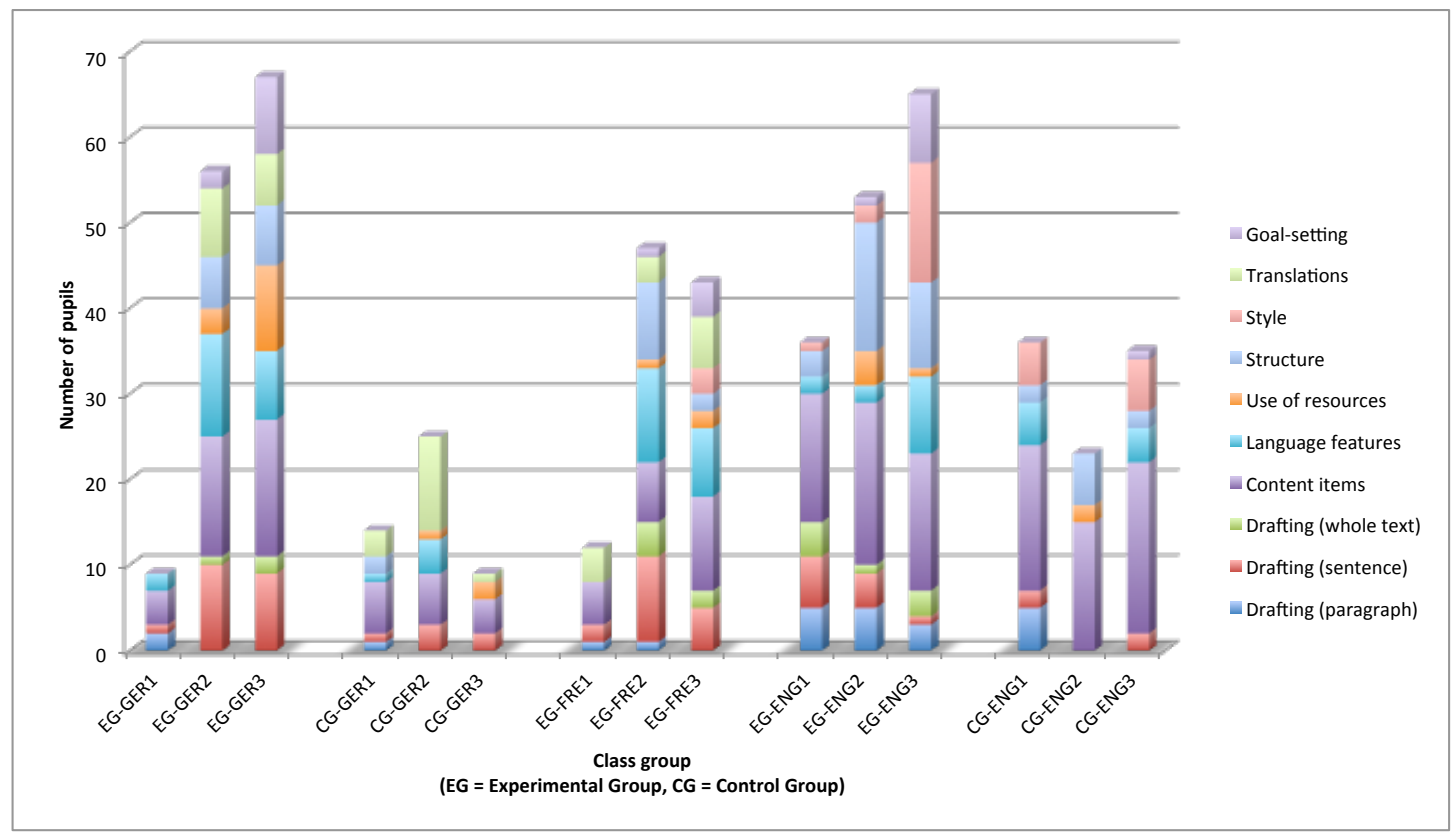

Figure 3: Range of planning strategies (by number of students) $)^{3}$

Results showed that the explicit SBI in the German classroom during Phase A of the intervention positively impacted the range of planning strategies the students used, not only in German, but also in French and, albeit to a lesser extent, English. The most noticeable change over time occurred in the EG German tasks between Points 1 and 2. From Points 2 to 3 these levels were maintained. Similar trends were evident in the French tasks, suggesting that students were transferring a range of planning strategies from one FL context to another, without any explicit encouragement to do so. It is also interesting to note that after Phase A of the intervention in the German classroom, there was evidence of an increase in both the frequency and range of planning strategies used by students in English. This suggests that some level of FL to L1 transfer did occur which affected the quality of planning. Overall, it seems as though the planning behaviours of the EG in German, French and English were becoming more similar over time, particularly in relation to the planning of content items, language features and goalsetting.

\footnotetext{
3 The number of students as indicated on the vertical axis may exceed the total number of students in a class as one student may have used several strategies.
} 


\subsection{Monitoring}

Monitoring strategies within the context of this study predominantly took the form of problem solving strategies such as using resources or asking for help during the writing process, as shown in Figure 4 (see Appendix B for table of frequencies).

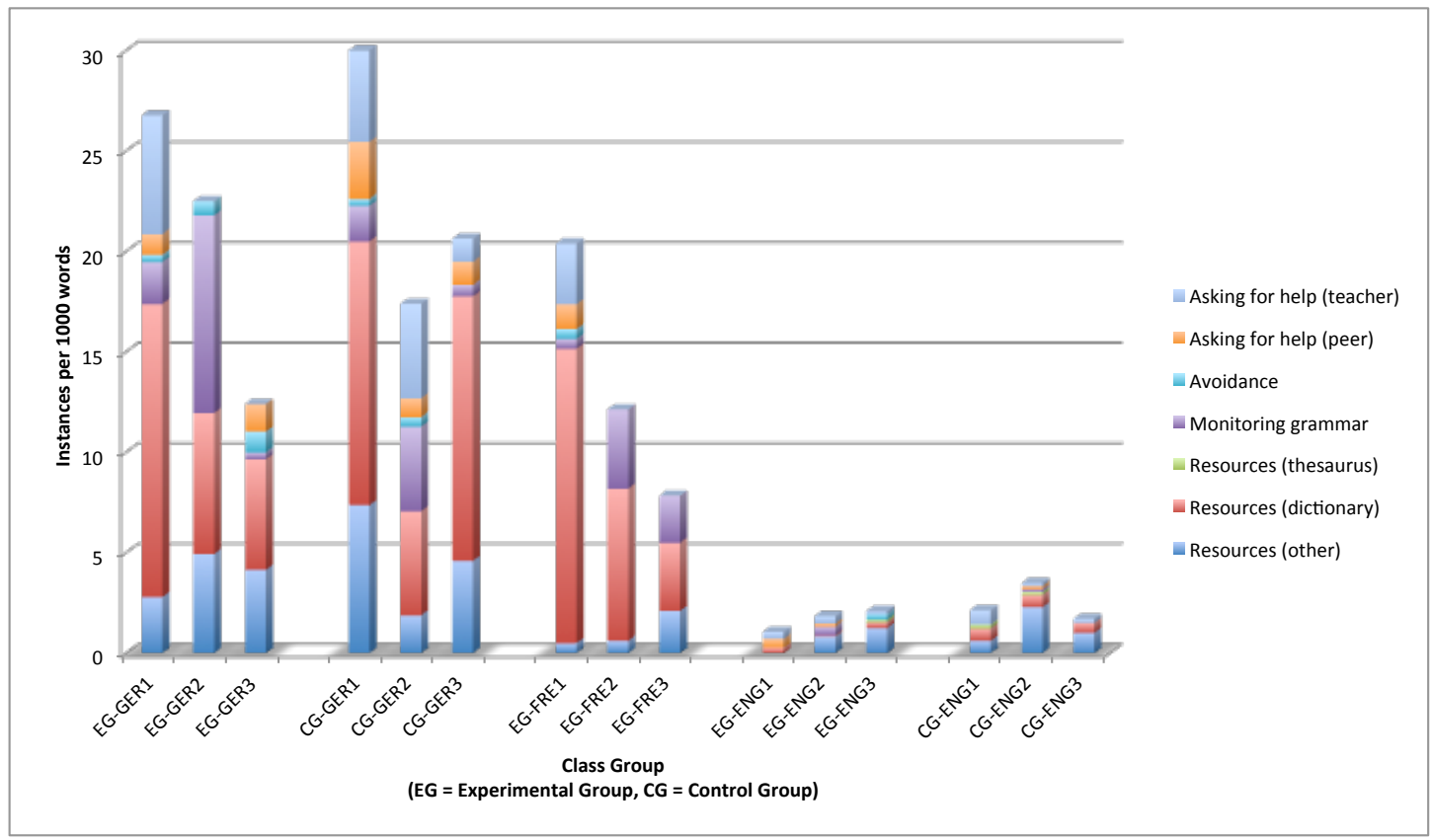

Figure 4: Instances of problem solving strategies (per 1000 words) ${ }^{4}$

At all stages, students engaged in such problem-solving strategies much more in the FLs than in the English tasks. This is to be expected considering that they were much less proficient in German and French and therefore much more likely to encounter problems when writing. However, it is also interesting to consider the trends which emerged within each language over time, particularly in the case of both FLs among the EG, where the use of problem solving strategies dropped between Points 1 and 2, and again between Points 2 and 3. This seemed surprising at first, as it would be expected that as the academic year and the level of difficulty increased, the instances of problem solving strategies would also have increased, or at the very least remained relatively

${ }^{4}$ Due to the difference in length of the L1 and FL tasks, the raw frequency counts did not allow for fair comparisons to be made between languages. In order to control for this, each code was recalculated as the average number of instances per 1000 words. 
consistent. However, upon closer examination, it seems as though the drop in the use of resources while writing corresponded to an increase in the use of resources while planning. This perhaps suggests a pre-empting of potential difficulties on the part of the students and shift of some of the problem-solving activities to the pre-writing stage, allowing more time to concentrate on fluency and accuracy while writing.

It also emerged that at Point 1 the students in the EG and CG were equally likely to ask a peer or the teacher for help in both German and English, but at Points 2 and 3 in German and Point 3 in English, the EG were less likely to ask for help and more likely to use resources to find the answer. This is perhaps indicative of the EG students becoming more independent learners in all languages over the course of the year. While similar patterns emerged once again in both German and French, suggesting a high level of FL FL transfer, transfer to English was not evident in relation to the monitoring strategies examined. One possible explanation for this is the comparatively low occurrence of any form of monitoring strategies in the English tasks. This may simply be due to the fact that students, on the whole, tend to encounter fewer problems when writing in their first language compared to a FL, however it could also be evidence of proceduralisation of strategy use.

\subsection{Errors and error correction}

While this section does not report on specific strategies per se, it aims to provide an objective measure of the effectiveness of a range of strategies used by students to improve the accuracy of their work, such as monitoring for accuracy, applying grammatical rules while writing, and using resources such as dictionaries to check spelling. Errors were coded in four categories: grammar, punctuation, spelling and vocabulary errors, and instances where a student self-corrected an error were also coded under the same categories.

Errors. Figure 5 shows the average number and type of errors made per 1000 words for each class group in each language (see Appendix $\mathrm{C}$ for table of frequencies). This figure considers only those errors which remained uncorrected in the final text and not those which were made and then corrected. It is worth noting that, unsurprisingly 
given the early stages of their learning, students in both classes made considerably more errors overall in their FL writing tasks than in their English tasks.

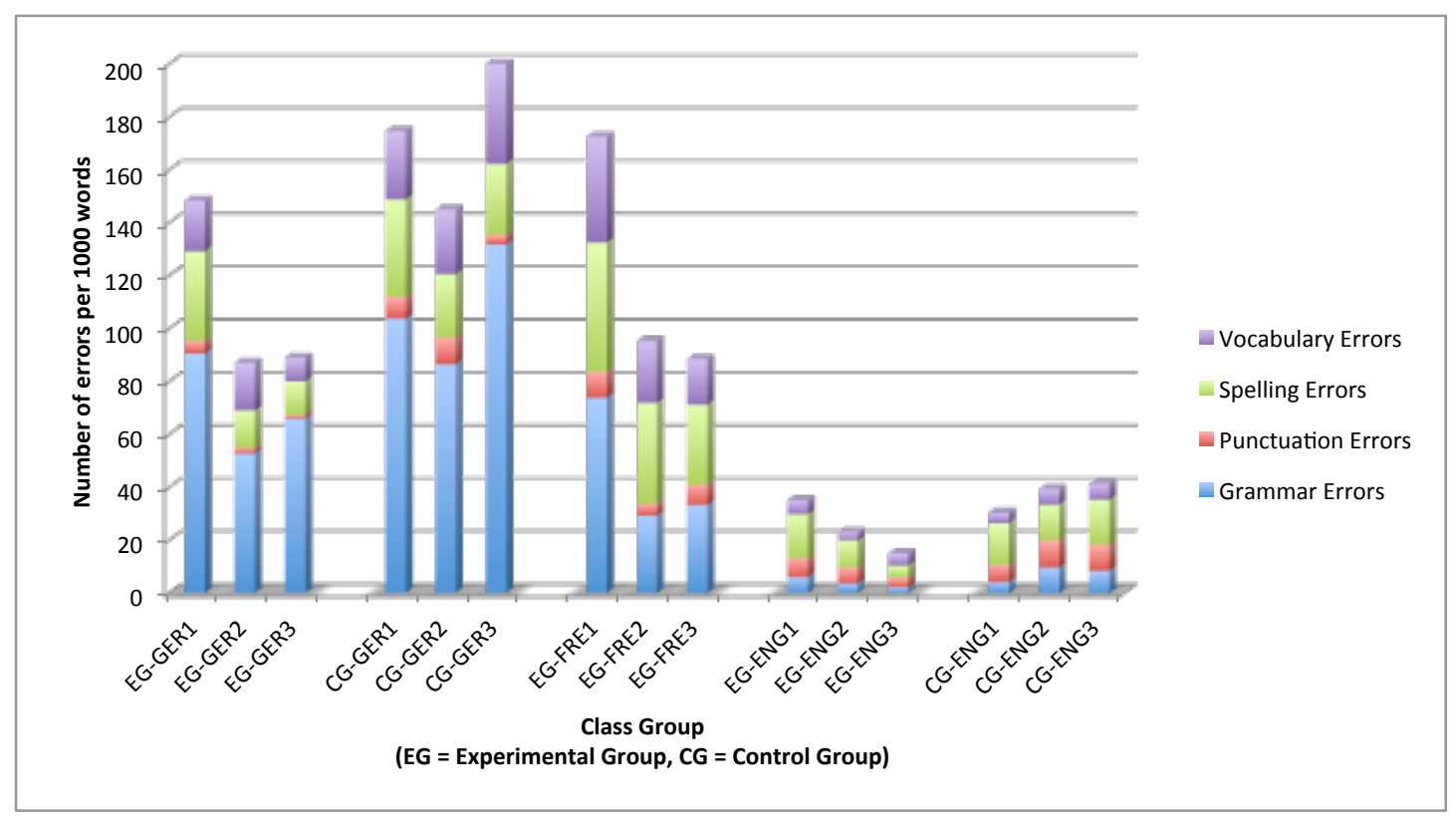

Figure 5: Number and type of errors (per 1000 words)

Results of a series of Mann-Whitney tests confirmed that there were no significant differences in the distribution of errors made by each class at Point 1 , which suggests that in terms of the level of accuracy of their work, both groups were comparable at the beginning (German: $Z=-.153, p=.879, r=-.02$; English: $Z=-1.022, p=.307, r=-.15$ ). It is also interesting to note that at Point 3 in German $(Z=-3.183, p=.001, r=-.49)$ and at both Points 2 and 3 in English $(Z=-2.115, p=.034, r=-.33$ and $Z=-2.947, p=.003$, $r=-.45$ respectively) the result is significant (with medium-large effect sizes), indicating that the EG made significantly fewer errors than the $\mathrm{CG}$ at these points.

A Friedman's ANOVA was conducted in order to examine more closely whether or not there was a significant difference in the distribution of errors within each group over time, as shown in Table 2. Results revealed that in all three languages for the EG there was a highly significant difference (i.e. reduction) in the number of errors made over time, which was not reflected in the CG. As suggested by Field (2009), this was investigated further by conducting a series of post hoc Wilcoxon signed-rank tests to look for differences at Points 1-2 and Points 2-3 and also to allow for calculation of effect size 
(see Appendix D). The most striking changes among the EG in all three languages occurred between Points 1 and 2 following the first phase of the intervention, with large effect sizes.

Table 2: Results of Friedman's ANOVA on errors made over time

\begin{tabular}{|l|c|c|c|c|}
\hline Subject & \multirow{2}{*}{ Class } & \multicolumn{3}{|c|}{ Friedman's ANOVA } \\
\cline { 3 - 5 } & & $\boldsymbol{F}_{\boldsymbol{r}}$ & df & $\boldsymbol{p}$ \\
\hline German & EG & 16.095 & 2 & $<.001$ \\
\cline { 2 - 5 } & CG & 4.023 & 2 & .134 \\
\hline \multirow{2}{*}{ French } & EG & 20.988 & 2 & $<.001$ \\
\hline English & EG & 16.900 & 2 & $<.001$ \\
\cline { 2 - 5 } & CG & 2.455 & 2 & .293 \\
\hline
\end{tabular}

Once again, the patterns for German and French were very similar, suggesting that the effects of a focus on accuracy as part of the SBI in the German classroom were readily transferred to French. Interestingly, however, for English, a drop in the number of errors also occurred after Phase A and this dropped even further after Phase B. This suggests that this may be a key area where students have transferred strategies introduced in the German classroom to English, without explicit encouragement to do so. Errors then further reduced as the strategy instruction was reinforced explicitly in the English classroom.

Error correction. In addition to considering the number of errors which remained in the final version of the tasks, it is also valuable to consider the extent to which students self-corrected their errors. This may act as an indicator of the students' level of metacognitive engagement with the text. If they are noticing and correcting errors themselves, either immediately after making them or while checking their work at the end, they are consciously evaluating the accuracy of what they have written. It emerged that while the number of errors being made by the EG in each subject decreased over time, the number of errors being self-corrected increased.

Table 3 shows the percentage of errors corrected for each class over time. Once again it is evident that both the EG and CG were relatively comparable at Point 1 and that students were more likely to notice and correct errors in English than in a FL. However, 
while the proportion of errors corrected by the CG generally decreased over time, it increased among the EG to the point where the students in this group self-corrected over half of all errors they made in English and around a quarter of all errors made in German and French.

Table 3: Percentage of errors corrected for each class over time

\begin{tabular}{|l|c|c|c|c|}
\hline \multirow{2}{*}{ Subject } & \multirow{2}{*}{ Class } & \multicolumn{3}{|c|}{ Percentage of errors corrected } \\
\cline { 3 - 5 } & & $\mathbf{1}$ & $\mathbf{2}$ & $\mathbf{3}$ \\
\hline \multirow{2}{*}{ German } & EG & $14.80 \%$ & $22.26 \%$ & $26.70 \%$ \\
\cline { 2 - 5 } & CG & $15.75 \%$ & $16.98 \%$ & $10.51 \%$ \\
\hline \multirow{2}{*}{ French } & EG & $11.53 \%$ & $18.02 \%$ & $23.13 \%$ \\
\hline \multirow{2}{*}{ English } & EG & $22.11 \%$ & $30.80 \%$ & $50.89 \%$ \\
\cline { 2 - 5 } & CG & $33 \%$ & $18.61 \%$ & $21.86 \%$ \\
\hline
\end{tabular}

\subsection{Evaluation}

Evaluation strategies within the context of this study are defined as the approach taken by students to check over their work and their focus while doing so. While there will inevitably be some overlap here with monitoring strategies, the aim was to attempt to distinguish between what students did while in the process of writing, and what they did to evaluate what they had written. In order to gather data about the evaluation strategies used by students, there were several questions at the end of each task sheet which asked them to indicate whether they checked their work, how they checked it and what they checked for. It is acknowledged that analysis of evaluation strategies relied more heavily on self-report data. However, when considered alongside the more objective data relating to errors and error correction it provides a valuable indication of students' perceptions of their strategy use.

Engagement in checking. First, it is worth considering the number of students who reported that they engaged in some form of evaluation of their work, as shown in Figure 6. 


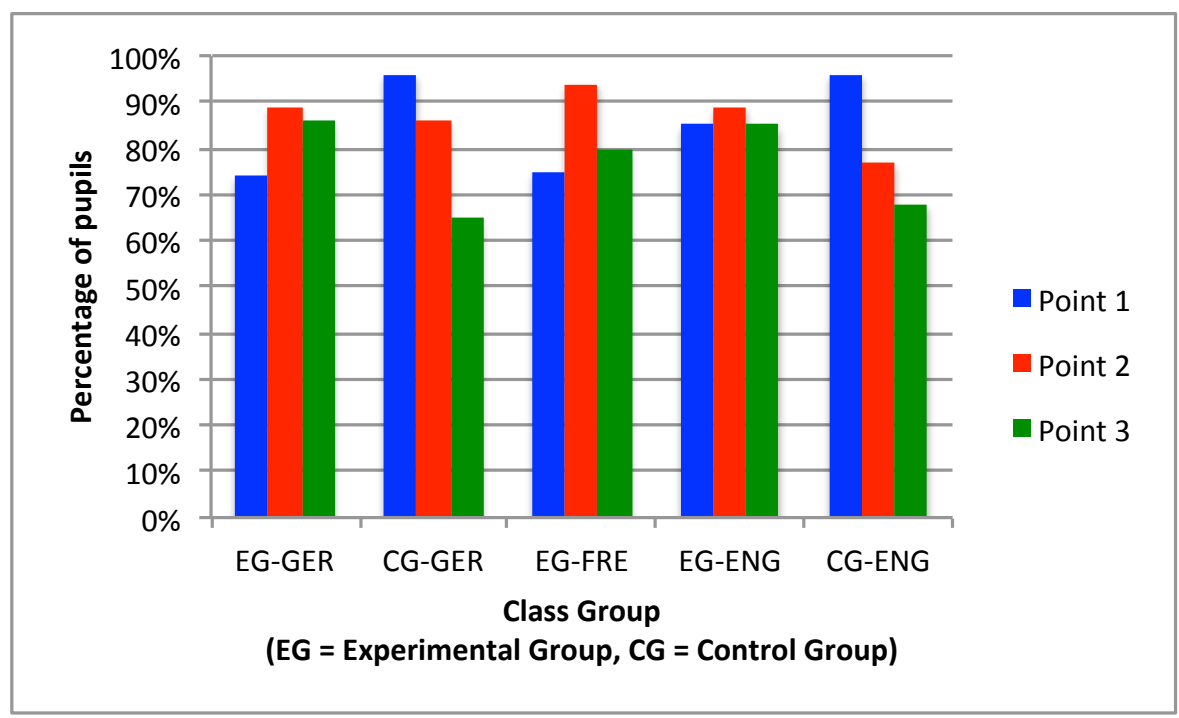

Figure 6: Percentage of students engaging in evaluation

One of the most striking features of Figure 6 is the very high proportion of students who reported having checked their work, which is relatively consistent across all subjects and time points. A series of McNemar tests confirmed that there were no significant differences between the proportion of students who reported engaging in any form of evaluation between Points 1 and 2, and Points 2 and 3 in any subject. However, it is important to acknowledge that students may have indicated that they checked their work simply because they felt this was the 'right' answer. It is therefore necessary to further examine their use of evaluation strategies in order to establish any possible effects or transfer of the SBI.

Focus of checking. In order to gather data on what students focused on while they were checking over their work, an open-ended question was included on the task sheet so as not to bias or restrict their responses. Figure 7 illustrates the range of evaluation strategies identified for each task, by the number of students who identified them (see Appendix E for table of frequencies). 


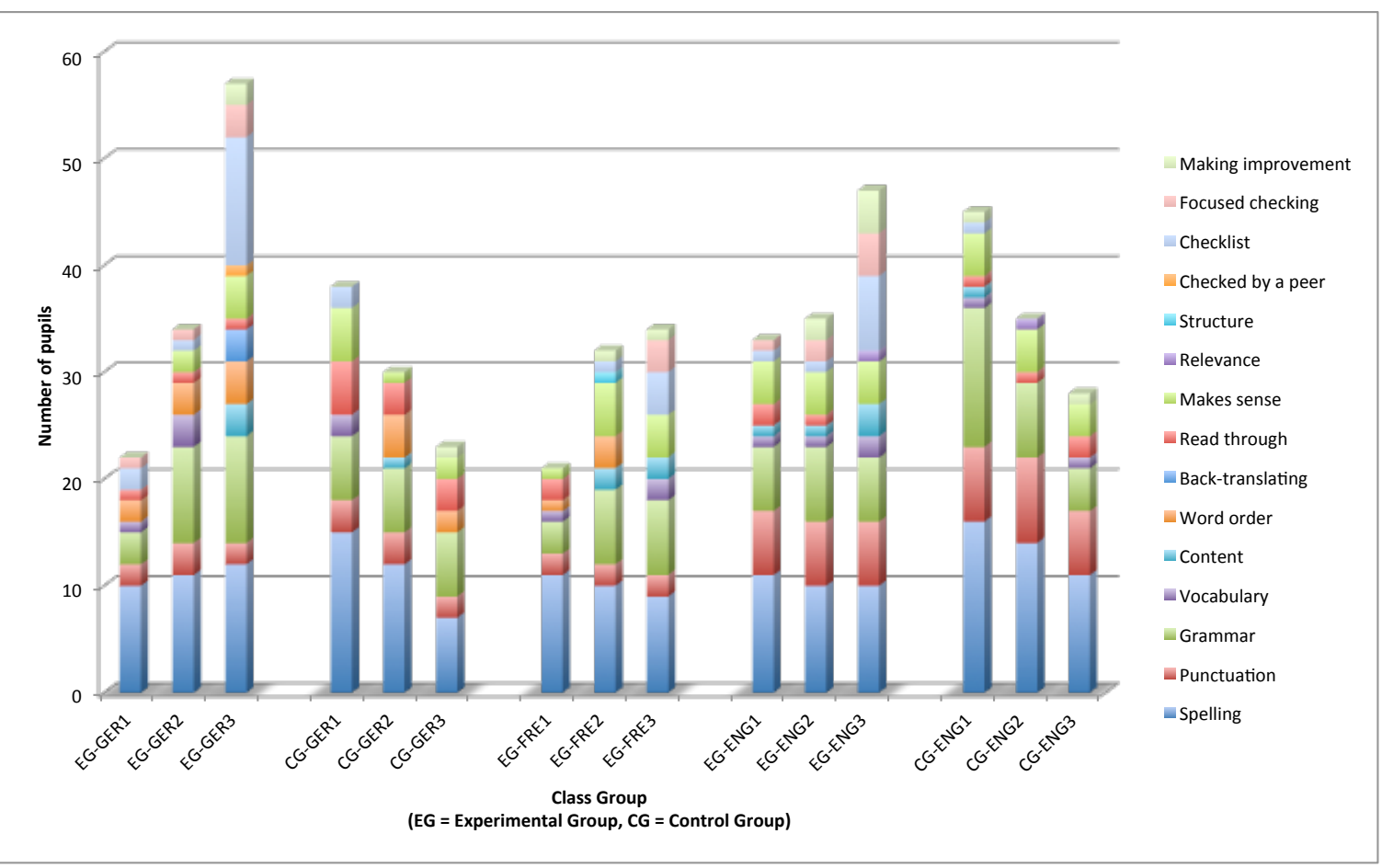

Figure 7: Range of evaluation strategies (by number of students)

It is interesting to note in the first instance, that at the beginning a higher number and wider range of evaluation foci were identified by both groups in English than in the FLs, even though students were undoubtedly aware that they were more likely to make errors while writing in German or French than in English. However, one notable commonality at this point was the predominance of checking for the more superficial features of spelling, punctuation and grammar. In all subjects at Point 1 these three features alone accounted for around $70 \%$ of what students said they checked for in their work.

In terms of change over time, once again one of the most striking shifts which occurred was in the number and range of foci identified by the EG students in German. This increased not only after Phase A of the intervention, but also continued to increase after Phase B. While the number of references to spelling, punctuation and grammar remained relatively static, the main increases related to what could perhaps be considered more 'higher level' evaluation strategies. These include, for example, engaging in more focused checking, where students identified particular areas where they had been prone to making errors and checked specifically for those. It seems that, at least to some extent, 
the effects of Phase A of the intervention also transferred to French, which highlights once again the FL - FL transfer. For the EG in English, an increase can also be observed; however this occurred between Points 2 and 3, which would suggest that it was a result of the explicit SBI in the English classroom during Phase B of the intervention, rather than any implicit transfer from German.

\section{Discussion}

\subsection{Limited transfer of pre-existing strategies from L1 - FL}

As discussed in Section 2.2, transfer between languages was originally conceptualised as the predominantly monodirectional transfer of pre-existing L1 skills to the FL. However, while some studies have reported a similarity in the writing process for individual learners across the L1 and the FL (e.g. Cumming 1989; Jones and Tetroe 1987) which may suggest some form of L1 - FL transfer, this was not particularly evident in the results of the current study. Given the differences between students' baseline approaches to writing in English and the FLs at Point 1, it seems as though learners were not necessarily transferring their $\mathrm{L} 1$ writing strategies automatically to a FL. This was particularly evident in relation to the planning phase; students were much more likely to engage in planning and use a wider range of strategies in English than in the FLs.

Differences also emerged in relation to monitoring strategies as the students used more problem-solving strategies when writing in the FLs, which is not surprising given that they were more likely to encounter problems in the FLs. Yet, it is also important to consider the possibility that the students were similarly engaging in a substantial number of problem-solving strategies when writing in English, although these may have become proceduralised over time and as a result may not have been self-reported during the data collection process. If this were the case, then the students' lack of awareness of their L1 problem-solving strategies would make it difficult for them to consciously transfer them to a FL context. 
It was in relation to the evaluation strategies that the students seemed to take a more similar approach across languages. At Point 1 the students were almost equally likely to report checking over their work in English and the FLs and to take a similar approach to checking their work. However, in terms of the focus of checking, a higher number and wider range of evaluation foci were identified by students in English than in the FLs. Students were therefore utilising a range of strategies in their L1 that they were not necessarily transferring independently to a FL context.

\subsection{The ease of FL - FL transfer}

The most evident form of transfer to emerge from this study was undoubtedly the FL - FL transfer, where students readily transferred strategies explicitly developed in the German classroom to their French writing.

This occurred relatively consistently throughout the year and across all categories of strategies: from the beginning, students used similar planning, monitoring and evaluation strategies in both FLs and although the development of strategy use over time was perhaps more marked in German, patterns of strategy use for French followed a very similar trend. Given that the students did not receive any explicit SBI in the French classroom, nor were they explicitly instructed in the German classroom to transfer their strategies to French, this process seemed to occur relatively automatically.

Such findings regarding the ease with which the EG students seemed to implicitly or automatically transfer strategies between two FL contexts also provide evidence to support Cenoz's (2001:8) suggestion that "the processes used in third language acquisition may be very similar to those used by L2 learners". This is particularly true for the current study where the students were at a similar stage of learning in both FLs and there is therefore little or no chronological or hierarchical distinction to be made between them.

\subsection{The development of FL - L1 transfer}


While there was little evidence of L1 - FL transfer at the beginning of this study, as discussed previously, the reverse was examined in two different forms; firstly, in relation to any FL - L1 transfer which took place implicitly following the intervention of SBI in the German classroom in Phase A and secondly, whether a period of explicit reinforcement of the SBI in the English classroom during Phase B facilitated such transfer.

Although the implicit FL - L1 transfer was not as evident as the implicit FL - FL transfer outlined in the previous section, there was evidence to suggest that students transferred some strategies developed in the German classroom to the English tasks without any explicit encouragement to do so. This was particularly evident in relation to the quality of planning, as indicated by an increase in both the frequency and range of planning strategies used by the EG, and an improvement in accuracy, as demonstrated by both a decrease in errors made and an increase in errors corrected. Such examples of implicit FL - L1 transfer have also been detected by Berman (1994) and Kesckes and Papp (2000) in relation to essay organisation skills and use of syntactic structures respectively. However, it is important to note that Kesckes and Papp (2000) only found such evidence of transfer among learners with a threshold level of proficiency in the FL. The participants of the current study, on the other hand, were relatively beginner language learners. A possible explanation for this is that Kesckes and Papp's study did not involve a specific intervention or writing instruction. Therefore, perhaps their hypothesis may hold true for the automatic transfer of writing features between languages, however the findings from the current study suggest that even relatively beginner or low proficiency FL learners can be taught in such a way as to encourage transfer and the development of multicompetence.

Similarly, it is also important to question why the current study provided stronger evidence of implicit transfer from the FL - L1 than from the L1 - FL. If, as James (2006) suggests, the development of metacognitive reflection is a key technique for encouraging transfer, then perhaps the FL classroom, where learners are more aware of being consciously and actively engaged in thinking about language, is a key context for developing transferable metacognitive writing strategies which can also benefit the L1 (see Forbes, in press). 
Yet the FL - L1 transfer was most evident in the current study when the links between strategy use were made explicit in both language contexts. Following Phase B of the intervention, there was a further increase in the number and range of planning strategies used by the EG in English, further improvement in the accuracy of their writing and an increase in the number and range of evaluation foci identified by students. However, given that the SBI took place in both the English and German classrooms during Phase B of the study, it is important to acknowledge the possibility of bidirectionality of transfer. Even though fewer changes took place in German and French at a whole-class level following Phase B of the intervention, some of these may have been the result of transfer from the L1 SBI. It is similarly important to acknowledge the difficulty of establishing transfer at all at this stage, as it may be that the instruction in the English classroom simply facilitated the concurrent development of strategies in a different context. Nevertheless, the evidence of a convergence of strategy use in L1 and the FLs over time among the EG indicated a move towards the "overlapping systems" (Cook 2002) characteristic of multicompetent writers.

\section{Conclusion}

This study sheds light on the possibility of the transfer of writing strategies between native and FL contexts, even for beginner, school-aged FL learners. Key findings indicate that the intervention of strategy-based instruction positively influenced the quantity and quality of students' strategy use in German, French and English. While L1 to FL transfer of writing strategies did not necessarily take place at the beginning of

the study, following the first phase of instruction in the German classroom a high level of FL to FL transfer was apparent across all areas. FL to L1 transfer was predominantly evident in relation to an improvement in the quality of students' planning and a reduction in the number of errors made. However, the most notable changes in English occurred following the second phase of the intervention, where the links between strategy use in the FLs and the L1 were made explicit.

Limitations in this study include the small sample size, and the absence of any French data from the CG means that indications of FL - FL transfer must be interpreted 
with caution. As with the majority of research into language learning strategies, the data in this study relies largely on self-report and therefore students may have been using other strategies they were not consciously aware of or which had become proceduralised.

However, the strong evidence of cross-linguistic transfer found here is convincing enough to warrant further investigation, for example, to explore whether this holds true if the two FLs are at different stages of development, or if there is a greater typological distance between the languages, such as French and Russian. The findings suggest not only that explicit strategy instruction can improve learner outputs, but also highlight the key role that FL teachers play in developing writing skills more generally. The evidence therefore calls for a collaborative and multilingual approach to writing pedagogy, where L1 and FL teachers work together to encourage and facilitate connection making across language contexts.

\section{Acknowledgements}

We are grateful to the ESRC for providing funding for the $\mathrm{PhD}$ study from which this paper is drawn. We would also like to thank the reviewers for their helpful comments and suggestions.

\section{References}

Ardasheva, Yuliya, Zhe Wang, Olusola O. Adesope \& Jeffrey C. Valentine. 2017. Exploring effectiveness and moderators of language learning strategy instruction on second language and self-regulated learning outcomes. Review of Educational Research 87(3). 544-582. doi:10.3102/0034654316689135.

Bereiter, Carl \& Marlene Scardamalia. 1987. The psychology of written composition. Hillsdale, NJ: Lawrence Erlbaum Associates Inc.

Berman, R. 1994. Learners' transfer of writing skills between languages. TESL Canada Journal/Revue TESL du Canada 12(1). 29-46.

Bialystok, Ellen. 1978. A theoretical model of second language learning. Language Learning 28(1). 69-83. 
Cenoz, Jasone. 2001. The effect of linguistic distance, L2 status and age on crosslinguistic influence in third language acquisition. In Jasone Cenoz, Britta Hufeisen \& Ulrike Jessner (eds.), Cross-linguistic influence in third language acquisition: psycholinguistic perspectives, 8-20. Clevedon: Multilingual Matters Ltd.

Cenoz, Jasone, Britta Hufeisen \& Ulrike Jessner. 2001. Introduction. In Jasone Cenoz, Britta Hufeisen \& Ulrike Jessner (eds.), Cross-linguistic influence in third language acquisition: psycholinguistic perspectives, 1-7. Clevedon: Multilingual Matters Ltd.

Chamot, Anna Uhl. 2005. Language learner strategy instruction: Current issues and research. Annual Review of Applied Linguistics 25. 112-130.

Cohen, A.D., S.J. Weaver \& T.Y. Li. 1998. The impact of strategies-based instruction on speaking a foreign language. In Andrew D. Cohen (ed.), Strategies in learning and using a second language. Harlow: Longman.

Cohen, Andrew D. 1998. Strategies in learning and using a second language. 1 st ed. Harlow: Longman.

Cohen, Andrew D. 2011. Strategies in learning and using a second language. 2nd ed. Harlow: Longman.

Cook, Vivian. 2002. Background to the L2 user. In Vivian Cook (ed.), Portraits of the L2 user, 1-28. Clevedon: Multilingual Matters Ltd.

Cook, Vivian. 2008. Multi-competence: Black hole or wormholw for second language acquisition research. In ZhaoHong Han (ed.), Understanding second language process, 16-26. Clevedon: Multilingual Matters Ltd.

Cumming, Alister. 1989. Writing expertise and second language proficiency. Language Learning 39(1). 81-141.

Cummins, James. 1979. Linguistic interdependence and the educational development of bilingual children. Review of Educational Research 49(2). 222-251.

Cummins, James. 1981. The role of primary language development in promoting educational success for language minority students. Schooling and language minority students: A theoretical framework. Los Angeles: Evaluation, Dissemination and Assessment Center, California State University.

Forbes, Karen. 2016. Cross-linguistic transfer of foreign language writing strategies: Developing first and foreign language writing through metacognitive strategy use. 
Cambridge, UK: University of Cambridge $\mathrm{PhD}$ thesis.

Forbes, Karen. 2018. The role of individual differences in the development and transfer of writing strategies between foreign and first language classrooms. Research Papers in Education. DOI: 10.1080/02671522.2018.1452963

Forbes, Karen. In press. "In German I have to think about it more than I do in English": The foreign language classroom as a key context for developing transferable metacognitive strategies. In Åsta Haukås, Camilla Bjørke \& Magne Dypedahl (eds.), Metacognition in Language Learning and Teaching. New York: Routledge.

Field, Andy. 2009. Discovering statistics using SPSS. 3rd ed. London: Sage Publications Ltd.

Flower, Linda \& John R. Hayes. 1981. A cognitive process theory of writing. College Composition and Communication 32(4). 365-387.

Grenfell, Michael \& Ernesto Macaro. 2007. Claims and critiques. In Andrew D. Cohen \& Ernesto Macaro (eds.), Language learner strategies: 30 years of research and practice, 9-28. Oxford: OUP.

Griffiths, Carol. 2013. The strategy factor in successful language learning. Bristol: Multilingual Matters Ltd.

Griffiths, Carol \& Rebecca L. Oxford. 2014. The twenty-first century landscape of language learning strategies: Introduction to this special issue. System 43. 1-10. doi:10.1016/j.system.2013.12.009.

James, Mark Andrew. 2006. Teaching for transfer in ELT. ELT Journal 60(2). 151-159. doi:10.1093/elt/cci102.

Jones, C.S. \& J. Tetroe. 1987. Composing in a second language. In A. Matsuhashi (ed.), Writing in real time, 34-57. New York: Addison-Wesley.

Kecskes, Istvan \& Tünde Papp. 2000. Foreign language and mother tongue. Mahwah, NJ: Lawrence Erlbaum Associates Inc.

Kellerman, Eric. 1991. Compensatory strategies in second language research: A critique, a revision, and some (non-) implications for the classroom. In Robert Phillipson, Eric Kellerman, Larry Selinker, Mike Sharwood Smith \& Merrill Swain (eds.), Foreign/second language pedagogy research: A commemorative volume for Claus Faerch, 142-161. Clevedon: Multilingual Matters Ltd. 
Macaro, Ernesto. 2001. Learning strategies in foreign and second language classrooms. London: Continuum.

Manchón, Rosa M. \& Pieter de Haan. 2008. Writing in foreign language contexts: An introduction. Journal of Second Language Writing 17(1). 1-6. doi:10.1016/j.jslw.2007.08.002.

O’Malley, J. Michael \& Anna Uhl Chamot. 1990. Learning strategies in second language acquisition. Cambridge: Cambridge University Press.

Odlin, Terence. 1989. Language transfer: Cross-linguistic influence in language learning. Cambridge: Cambridge University Press.

Oxford, Rebecca. 2011. Teaching and researching language learning strategies. Harlow: Pearson Education.

Oxford, Rebecca. 2017. Teaching and researching language learning strategies: Selfregulation in context. New York: Routledge.

Plonsky, Luke. 2011. The effectiveness of second language strategy instruction : A metaanalysis. Language Learning 61(4). 993-1038. doi:10.1111/j.14679922.2011.00663.x.

Pomphrey, Cathy. 2000. Language transfer and the Modern Foreign Languages curriculum. Issues in Modern Foreign Languages teaching, 269-282. London: RoutledgeFalmer.

Rinnert, Carol, Hiroe Kobayashi \& Akemi Katayama. 2015. Argumentation text construction by Japanese as a Foreign Language writers: a dynamic view of transfer. The Modern Language Journal 99(2). 213-245. doi:10.1111/mod1.12210. http://doi.wiley.com/10.1111/modl.12210.

Rubin, Joan, Anna Uhl Chamot, Vee Harris \& Neil J. Anderson. 2007. Intervening in the use of strategies. In Andrew D. Cohen \& Ernesto Macaro (eds.), Language learner strategies: 30 years of research and practice, 141-160. Oxford: OUP.

Williams, Jessica. 2012. The potential role(s) of writing in second language development. Journal of Second Language Writing 21(4). Elsevier Inc. 321-331. doi:10.1016/j.jslw.2012.09.007. http://dx.doi.org/10.1016/j.jslw.2012.09.007. 


\section{Appendices}

Appendix A: Table of frequencies for Figure 3: Range of planning strategies (by number of students)

\begin{tabular}{|l|l|l|l|l|l|l|l|l|l|l|l|l|l|l|l|l|}
\hline Language & \multicolumn{9}{|c|}{ German } & \multicolumn{3}{c|}{ French } & \multicolumn{5}{c|}{ English } \\
\hline Group & \multicolumn{3}{|c|}{ EG } & \multicolumn{3}{|c|}{ CG } & \multicolumn{3}{|c|}{ EG } & \multicolumn{3}{|c|}{ EG } & \multicolumn{3}{|c|}{ CG } \\
\hline Point & $\mathbf{1}$ & $\mathbf{2}$ & $\mathbf{3}$ & $\mathbf{1}$ & $\mathbf{2}$ & $\mathbf{3}$ & $\mathbf{1}$ & $\mathbf{2}$ & $\mathbf{3}$ & $\mathbf{1}$ & $\mathbf{2}$ & $\mathbf{3}$ & $\mathbf{1}$ & $\mathbf{2}$ & $\mathbf{3}$ \\
\hline Drafting (paragraph) & 2 & 0 & 0 & 1 & 0 & 0 & 1 & 1 & 0 & 5 & 5 & 3 & 5 & 0 & 0 \\
\hline Drafting (sentence) & 1 & 10 & 9 & 1 & 3 & 2 & 2 & 10 & 5 & 6 & 4 & 1 & 2 & 0 & 2 \\
\hline Drafting (whole text) & 0 & 1 & 2 & 0 & 0 & 0 & 0 & 4 & 2 & 4 & 1 & 3 & 0 & 0 & 0 \\
\hline Content items & 4 & 14 & 16 & 6 & 6 & 4 & 5 & 7 & 11 & 15 & 19 & 16 & 17 & 15 & 20 \\
\hline Language features & 2 & 12 & 8 & 1 & 4 & 0 & 0 & 11 & 8 & 2 & 2 & 9 & 5 & 0 & 4 \\
\hline Use of resources & 0 & 3 & 10 & 0 & 1 & 2 & 0 & 1 & 2 & 0 & 4 & 1 & 0 & 2 & 0 \\
\hline Structure & 0 & 6 & 7 & 2 & 0 & 0 & 0 & 9 & 2 & 3 & 15 & 10 & 2 & 6 & 2 \\
\hline Style & 0 & 0 & 0 & 0 & 0 & 0 & 0 & 0 & 3 & 1 & 2 & 14 & 5 & 0 & 6 \\
\hline Translations & 0 & 8 & 6 & 3 & 11 & 1 & 4 & 3 & 6 & 0 & 0 & 0 & 0 & 0 & 0 \\
\hline Goal-setting & 0 & 2 & 9 & 0 & 0 & 0 & 0 & 1 & 4 & 0 & 1 & 8 & 0 & 0 & 1 \\
\hline Total & $\mathbf{9}$ & $\mathbf{5 6}$ & $\mathbf{6 7}$ & $\mathbf{1 4}$ & $\mathbf{2 5}$ & $\mathbf{9}$ & $\mathbf{1 2}$ & $\mathbf{4 7}$ & $\mathbf{4 3}$ & $\mathbf{3 6}$ & $\mathbf{5 3}$ & $\mathbf{6 5}$ & $\mathbf{3 6}$ & $\mathbf{2 3}$ & $\mathbf{3 5}$ \\
\hline
\end{tabular}


Appendix B: Table of frequencies for Figure 4: Instances of problem solving strategies (per 1000 words)

\begin{tabular}{|l|c|c|c|c|c|c|c|c|c|c|c|c|c|c|c|}
\hline Language & \multicolumn{5}{|c|}{ German } & \multicolumn{3}{c|}{ French } & \multicolumn{5}{c|}{ English } \\
\hline Group & \multicolumn{3}{|c|}{ EG } & \multicolumn{3}{|c|}{ CG } & \multicolumn{3}{c|}{ EG } & \multicolumn{3}{c|}{ EG } \\
\hline Point & $\mathbf{1}$ & $\mathbf{2}$ & $\mathbf{3}$ & $\mathbf{1}$ & $\mathbf{2}$ & $\mathbf{3}$ & $\mathbf{1}$ & $\mathbf{2}$ & $\mathbf{3}$ & $\mathbf{1}$ & $\mathbf{2}$ & $\mathbf{3}$ & $\mathbf{1}$ & $\mathbf{2}$ & $\mathbf{3}$ \\
\hline $\begin{array}{l}\text { Resources } \\
\text { (other) }\end{array}$ & 2.78 & 4.92 & 4.14 & 7.36 & 1.88 & 4.58 & 0.49 & 0.61 & 2.1 & 0 & 0.81 & 1.25 & 0.61 & 2.28 & 1 \\
\hline $\begin{array}{l}\text { Resources } \\
\text { (dictionary) }\end{array}$ & 14.6 & 7.03 & 5.51 & 13.13 & 5.17 & 13.18 & 14.66 & 7.58 & 3.39 & 0.26 & 0.07 & 0.28 & 0.61 & 0.61 & 0.5 \\
\hline $\begin{array}{l}\text { Resources } \\
\text { (thesaurus) }\end{array}$ & 0 & 0 & 0 & 0 & 0 & 0 & 0 & 0 & 0 & 0 & 0 & 0.14 & 0.2 & 0.15 & 0 \\
\hline $\begin{array}{l}\text { Monitoring } \\
\text { grammar }\end{array}$ & 2.09 & 9.84 & 0.34 & 1.77 & 4.23 & 0.57 & 0.49 & 3.94 & 2.34 & 0 & 0.44 & 0 & 0 & 0.15 & 0 \\
\hline Avoidance & 0.35 & 0.7 & 1.03 & 0.35 & 0.47 & 0 & 0.49 & 0 & 0 & 0 & 0 & 0.28 & 0 & 0 & 0 \\
\hline $\begin{array}{l}\text { Ask help } \\
\text { (peer) }\end{array}$ & 1.04 & 0 & 1.38 & 2.84 & 0.94 & 1.15 & 1.24 & 0 & 0 & 0.45 & 0.15 & 0 & 0 & 0.15 & 0 \\
\hline $\begin{array}{l}\text { Ask help } \\
\text { (teacher) }\end{array}$ & 5.91 & 0 & 0 & 4.61 & 4.7 & 1.15 & 3.02 & 0 & 0 & 0.34 & 0.37 & 0.14 & 0.71 & 0.15 & 0.2 \\
\hline Total & $\mathbf{2 6 . 7 7}$ & $\mathbf{2 2 . 4 9}$ & $\mathbf{1 2 . 4}$ & $\mathbf{3 0 . 0 6}$ & $\mathbf{1 7 . 3 9}$ & $\mathbf{2 0 . 6 3}$ & $\mathbf{2 0 . 3 9}$ & $\mathbf{1 2 . 1 3}$ & $\mathbf{7 . 8 3}$ & $\mathbf{1 . 0 5}$ & $\mathbf{1 . 8 4}$ & $\mathbf{2 . 0 9}$ & $\mathbf{2 . 1 3}$ & $\mathbf{3 . 4 9}$ & $\mathbf{1 . 7}$ \\
\hline
\end{tabular}


Appendix C: Table of frequencies for Figure 5: Number and type of errors (per 1000 words)

\begin{tabular}{|c|c|c|c|c|c|c|c|c|c|c|c|c|c|c|c|}
\hline \multirow{3}{*}{$\begin{array}{l}\text { Language } \\
\text { Group } \\
\text { Point }\end{array}$} & \multicolumn{6}{|c|}{ German } & \multirow{2}{*}{\multicolumn{3}{|c|}{$\begin{array}{c}\text { French } \\
\text { EG }\end{array}$}} & \multicolumn{6}{|c|}{ English } \\
\hline & \multicolumn{3}{|c|}{ EG } & \multicolumn{3}{|c|}{ CG } & & & & \multicolumn{3}{|c|}{ EG } & \multicolumn{3}{|c|}{ CG } \\
\hline & 1 & 2 & 3 & 1 & 2 & 3 & 1 & 2 & 3 & 1 & 2 & 3 & 1 & 2 & 3 \\
\hline Grammar & 90.40 & 52.72 & 65.82 & 103.62 & 86.55 & 131.81 & 73.77 & 29.09 & 33.20 & 5.88 & 3.62 & 2.08 & 4.16 & 9.58 & 8.27 \\
\hline Punctuation & 4.87 & 2.11 & 1.38 & 8.16 & 9.88 & 3.44 & 9.77 & 4.55 & 7.81 & 7.24 & 5.83 & 3.74 & 6.39 & 10.19 & 9.90 \\
\hline Spelling & 33.73 & 14.06 & 12.75 & 36.91 & 23.99 & 26.93 & 48.85 & 38.18 & 30.08 & 16.52 & 10.34 & 4.43 & 15.73 & 13.53 & 17.00 \\
\hline Vocabulary & 19.12 & 17.93 & 8.96 & 25.90 & 24.46 & 37.82 & 40.06 & 23.33 & 17.19 & 5.36 & 3.10 & 4.57 & 3.96 & 5.93 & 6.05 \\
\hline Total & 148.12 & 86.82 & 88.90 & 174.59 & 144.87 & 200.00 & 172.45 & 95.15 & 88.28 & 35.00 & 22.89 & 14.82 & 30.25 & 39.22 & 41.22 \\
\hline
\end{tabular}

Appendix D: Results of Wilcoxon signed rank tests on errors made over time

\begin{tabular}{|l|c|c|c|c|c|c|c|}
\hline Subject & \multirow{2}{*}{ Class } & \multicolumn{3}{|c|}{ Point 1 - Point 2 } & \multicolumn{3}{c|}{ Point 2 - Point 3 } \\
\cline { 3 - 8 } & & $\mathbf{Z}$ & $\boldsymbol{p}$ & $\boldsymbol{r}$ & $\mathbf{Z}$ & $\boldsymbol{p}$ & $\boldsymbol{r}$ \\
\hline \multirow{2}{*}{ German } & EG & -3.493 & $\mathbf{. 0 0 0 *}$ & -.76 & -.122 & .903 & -.03 \\
\cline { 2 - 8 } & CG & -1.977 & $\mathbf{. 0 4 8}$ & -.41 & -1.894 & .058 & -.40 \\
\hline \multirow{2}{*}{ French } & EG & -3.424 & $<.001^{*}$ & -.75 & .000 & 1.000 & 0 \\
\hline English & EG & -3.099 & $\mathbf{. 0 0 2} *$ & -.69 & -2.315 & $\mathbf{. 0 2 1}$ & -.52 \\
\cline { 2 - 8 } & CG & -1.704 & .088 & -.36 & -0.828 & .408 & -.18 \\
\hline
\end{tabular}

*These results remain significant when using Bonferroni adjusted $p$ levels of .005 
Appendix E: Table of frequencies for Figure 7: Range of evaluation strategies (by number of students)

\begin{tabular}{|c|c|c|c|c|c|c|c|c|c|c|c|c|c|c|c|}
\hline \multirow{3}{*}{$\begin{array}{l}\text { Language } \\
\text { Group } \\
\text { Point }\end{array}$} & \multicolumn{6}{|c|}{ German } & \multirow{2}{*}{\multicolumn{3}{|c|}{$\begin{array}{c}\text { French } \\
\mathbf{E G}\end{array}$}} & \multicolumn{6}{|c|}{ English } \\
\hline & \multicolumn{3}{|c|}{ EG } & \multicolumn{3}{|c|}{$\mathbf{C G}$} & & & & \multicolumn{3}{|c|}{ EG } & \multicolumn{3}{|c|}{ CG } \\
\hline & 1 & 2 & 3 & 1 & 2 & 3 & 1 & 2 & 3 & 1 & 2 & 3 & 1 & 2 & 3 \\
\hline Spelling & 10 & 11 & 12 & 15 & 12 & 7 & 11 & 10 & 9 & 11 & 10 & 10 & 16 & 14 & 11 \\
\hline Punctuation & 2 & 3 & 2 & 3 & 3 & 2 & 2 & 2 & 2 & 6 & 6 & 6 & 7 & 8 & 6 \\
\hline Grammar & 3 & 9 & 10 & 6 & 6 & 6 & 3 & 7 & 7 & 6 & 7 & 6 & 13 & 7 & 4 \\
\hline Vocabulary & 1 & 3 & 0 & 2 & 0 & 0 & 1 & 0 & 2 & 1 & 1 & 2 & 1 & 0 & 1 \\
\hline Content & 0 & 0 & 3 & 0 & 1 & 0 & 0 & 2 & 2 & 1 & 1 & 3 & 1 & 0 & 0 \\
\hline Word order & 2 & 3 & 4 & 0 & 4 & 2 & 1 & 3 & 0 & 0 & 0 & 0 & 0 & 0 & 0 \\
\hline Back-translating & 0 & 0 & 3 & 0 & 0 & 0 & 0 & 0 & 0 & 0 & 0 & 0 & 0 & 0 & 0 \\
\hline Read through & 1 & 1 & 1 & 5 & 3 & 3 & 2 & 0 & 0 & 2 & 1 & 0 & 1 & 1 & 2 \\
\hline Makes sense & 0 & 2 & 4 & 5 & 1 & 2 & 1 & 5 & 4 & 4 & 4 & 4 & 4 & 4 & 3 \\
\hline Relevance & 0 & 0 & 0 & 0 & 0 & 0 & 0 & 0 & 0 & 0 & 0 & 1 & 0 & 1 & 0 \\
\hline Structure & 0 & 0 & 0 & 0 & 0 & 0 & 0 & 1 & 0 & 0 & 0 & 0 & 0 & 0 & 0 \\
\hline Checked by a peer & 0 & 0 & 1 & 0 & 0 & 0 & 0 & 0 & 0 & 0 & 0 & 0 & 0 & 0 & 0 \\
\hline Checklist & 2 & 1 & 12 & 2 & 0 & 0 & 0 & 1 & 4 & 1 & 1 & 7 & 1 & 0 & 0 \\
\hline Focused checking & 1 & 1 & 3 & 0 & 0 & 0 & 0 & 0 & 3 & 1 & 2 & 4 & 0 & 0 & 0 \\
\hline Making improvement & 0 & 0 & 2 & 0 & 0 & 1 & 0 & 1 & 1 & 0 & 2 & 4 & 1 & 0 & 1 \\
\hline Total & 22 & 34 & 57 & 38 & 30 & 23 & 21 & 32 & 34 & 33 & 35 & 47 & 45 & 35 & 28 \\
\hline
\end{tabular}

